\title{
O eu e a nova língua: identidades e ensino/aprendizagem de língua estrangeira
}

\author{
Letícia Coroa do COUTO \\ Universidade de Brasília \\ leticiacoroa@gmail.com
}

\begin{abstract}
Resumo
O modo como os alunos se posicionam diante da aprendizagem de uma LE pode exercer uma grande influência em seu processo de aquisição. As identidades determinam como a relação de professores e alunos com o mundo é construída no tempo e no espaço (NORTON, 2000), de forma que permeiam todo o processo de ensino/aprendizagem. As identidades têm também estreita relação com o contexto, sendo socialmente construídas, influenciando as ações e interações e sendo por elas influenciadas (HALL, 2000; MOITA LOPES, 2003; NORTON, 2000; SILVA, 2000; WOODWARD, 2000). O objetivo deste trabalho é sensibilizar os agentes do processo de ensino/aprendizagem de LE para a importância da questão das identidades nesse processo. Dessa maneira, novas pesquisas podem ser realizadas para que possamos conhecer mais sobre essa complexa teia de relações e (re)construções identitárias que pode influenciar o ensino/aprendizagem de LE e, assim, propor melhorias nesse processo.
\end{abstract}

Palavras-chave: ensino/aprendizagem de LE; identidades; construção identitária

\begin{abstract}
Students' attitudes towards a FL they are learning can have considerable influence on the language acquisition process. Identities determine how teachers' and students' relationship with the world is built across time and space (NORTON, 2000), and so they permeate the whole teaching/learning process. They also bear a close relationship with the context, and are socially constructed, thus influencing actions and interactions, while also being influenced by them (HALL, 2000; MOITA LOPES, 2003; NORTON, 2000; SILVA, 2000; WOODWARD, 2000). The goal of this work is to sensitize the agents in the FL teaching/learning process to the importance of the issue of
\end{abstract}


identities. Thus, further research may be carried out for a better understanding of this complex web of relationships and (re)constructions that can influence the whole FL teaching/learning process, and thereby advance improvements to it.

Keywords: foreign language teaching and learning; identity

\section{O ser na pesquisa}

Identidades têm sido estudadas em diferentes áreas do conhecimento, tais como Filosofia, Psicologia, Psicanálise, Antropologia, Sociolinguística, Análise do Discurso, Linguística Aplicada, entre outras. No contexto internacional, há trabalhos sobre identidades de professores (RICHARDS, 2006), sobre coconstrução de identidades de falantes não nativos (PARK, 2007; VARONIS; GASS, 1985), sobre identidades de aprendizes de LE (ALLENDOERFER, 1999; DUFF, 2002; SIEGEL, 1996; TSE, 1996), entre outros. No campo da LA no Brasil, diversas teses e dissertações vêm sendo defendidas acerca de temas como identidades de professores (CAVALLARI, 2002; ECKERT-HOFF, 2004; ROSSI, 2004; SOUSA, 2006; TÁPIAS-OLIVEIRA, 2006), identidades e internet (CASTRO, 2006), identidade indígena (FREITAS, 2004) e identidades de aprendizes de português-L2 (FONSECA, 2002; PEREIRA, 2005) e de francês (OLIVEIRA, 2008). Grande parte desses trabalhos utiliza as narrativas como instrumento de reconstrução de histórias de vida e de quem somos para nós e para nossos interlocutores.

No que se refere às pesquisas sobre a questão da identidade e LE, estas se orientam por diferentes abordagens em relação ao conceito de identidade, porém a maioria dos estudos acerca de identidades de aprendizes parece ter como pano de fundo a interação em LE, ou seja, a coconstrução da identidade nos discursos e negociações de alunos de LE na língua-alvo.

No contexto de sala de aula de LE, pesquisar identidades pode promover a reflexão de alunos e professores sobre como as diversas identidades influenciam no processo de ensino/aprendizagem. Este artigo traz reflexões teóricas sobre a relação entre identidades e ensino/aprendizagem de LE que podem contribuir para futuras pesquisas empíricas, para que assim se possa entender cada vez melhor 
esse processo e desenvolver adaptações e adequações metodológicas, institucionais e conceituais.

Moita Lopes (2003, p. 19) aponta que a temática das identidades surge nos estudos linguísticos com uma concepção de linguagem como discurso, ou seja, "uma concepção que coloca como central o fato de que todo uso da linguagem envolve ação humana em relação a alguém em um contexto interacional específico". Segundo o autor, "todo ato discursivo se dirige a alguém e toda prática discursiva é situada no mundo sócio-histórico e cultural em que ocorre, isto é, não ocorre em um vácuo social" (MOITA LOPES, 2003, p. 22). SerraniInfante (1998) afirma que o discurso é um modo de afirmação dos sistemas simbólicos que dão ordem à vida social e no qual o significado é produzido. Assim, para compreender a relação entre identidade e LE, é necessário trabalhar os processos identificatórios do sujeito-aluno e sua relação com a língua e o discurso.

Segundo Norton, tem-se assumido que a motivação do aprendiz é determinada por suas atitudes perante a comunidade falante da língua-alvo e que os níveis de ansiedade determinam "o quanto de insumo compreensível torna-se recepção cognitiva" (2000, p. 3, grifos no original $)^{2}$. Como afirma a autora, o problema da pesquisa sobre identidades é a pouca relevância que se dá ao aspecto socioconstrucionista das identidades, pois

muitos [teóricos] assumiram que o aprendiz pode sem problemas ser definido como motivado ou não-motivado, introvertido ou extrovertido, inibido ou desinibido, sem considerar que tais fatores afetivos são frequentemente socialmente construídos em inesgotáveis relações de poder, mudando através do tempo e do espaço, e possivelmente coexistindo de maneiras contraditórias em um único indivíduo ${ }^{3}$ (NORTON, 2000, p. 5).

\footnotetext{
${ }^{1}$ Do original: "[...] how much comprehensible input becomes cognitive intake".

2 Todas as traduções de citações literais são minhas.

3 Do original: "Many [theorists] have assumed that learner can be defined unproblematically as motivated or unmotivated, introverted or extroverted, inhibited or uninhibited, without considering that such affective factors are frequently socially constructed in inequitable relations of power, changing over time and space, and possibly coexisting in contradictory ways in a single individual".
} 
A mesma autora sugere que essa confusão se dá por serem feitas distinções artificiais entre o indivíduo e o contexto social, e que as pesquisas ainda não abordam adequadamente questões como: a) porque os aprendizes de língua oscilam entre motivados, extrovertidos e confiantes e desmotivados, introvertidos e ansiosos; b) porque em um contexto pode haver distância social entre determinado grupo de aprendizes de língua e a comunidade de falantes da língua-alvo, enquanto em outro contexto essa distância social pode ser mínima; ou c) porque um aprendiz em alguns momentos consegue falar e em outros permanece em silêncio (PEIRCE, 1995).

No entanto, há pesquisas sobre identidades que mostram que os processos de identificação cultural são complexos e intimamente relacionados ao contexto, e que identidade é um construto abstrato, não quantificável, simbólico (MOITA LOPES, 2003; SILVA, 2000). Esses processos de identificação cultural ocorrem em uma constante negociação de significado, em que exercemos identidades sociais de classe social, gênero, orientação sexual, raça, idade, profissão etc., simultaneamente em práticas discursivas diferentes ou não (MOITA LOPES, 2003, p. 309). Segundo o autor, a escolha de nossas múltiplas identidades é determinada pelas diferentes práticas discursivas, impregnadas pelo poder, nas quais agimos "através de papéis de identidades sociais diferentes e contraditórios".

Nessa inextrincável relação, o aluno constrói suas identidades e sua postura quanto à sua aprendizagem. Por isso, a pesquisa sobre identidades relacionadas ao processo de ensino/aprendizagem de LE tem muito a contribuir para o arcabouço teórico da área, pois, como aponta Peirce (1995, p. 11), “devido às distinções dicotômicas entre o aprendiz de língua e o mundo social, existem divergências na literatura sobre como as variáveis afetivas interagem com o contexto social maior" e ainda não se explorou o quanto as intermináveis relações de poder limitam as oportunidades que aprendizes de língua têm de usar a língua-alvo (PEIRCE, 1995).

As identidades determinam como a relação de alunos e professores com o mundo é construída e determinam também o modo

\footnotetext{
${ }^{4}$ Do original: "Because of the dichotomous distinctions between the language learner and the social world, there are disagreements in the literature on the way affective variables interact with the larger social context".
} 
como alunos se posicionam diante de sua aprendizagem. Dessa maneira, as identidades permeiam todo o processo de ensino/aprendizagem e podem exercer grande influência sobre ele. Vejamos a seguir como os conceitos e as características das identidades vêm sendo tratados nos estudos.

\section{Conceitos e características das identidades}

Diversos autores relacionam identidade e subjetividade com multiplicidade e discurso dentro de determinados contextos (HALL, 2000; MOITA LOPES, 2003; NORTON, 2000; PEIRCE, 1995; SILVA, 2000; WOODWARD, 2000). Hall (2000) utiliza o termo identidade como "o ponto de sutura" entre os discursos e as práticas nas quais assumimos lugares como sujeitos sociais e os processos que nos constroem como sujeitos de interação.

No âmbito de pesquisas com LE, Norton (2000, p. 5) refere-se à identidade como sendo o modo "como uma pessoa entende seu relacionamento com o mundo, como esse relacionamento é construído pelo tempo e espaço, e como a pessoa entende as possibilidades para o futuro $5 "$. Esse conceito traz um processo de identificação pessoal com o mundo, localizado no espaço e no tempo simbólicos (HALL, 2003), pois, como afirma Woodward (2000), toda prática social é simbolicamente marcada. Segundo a autora, "as identidades são diversas e cambiantes, tanto nos contextos sociais nos quais elas são vividas quanto nos sistemas simbólicos por meio dos quais damos sentido a nossas próprias posições" (WOODWARD, 2000, p. 33).

Podemos perceber também que o construto identidade é altamente abstrato e ainda volátil por estar constantemente em construção, na afirmação de Moita Lopes (2003, p. 28), de que "as identidades sociais devem ser entendidas [...] como um feixe de traços identitários que coexistem, às vezes de forma contraditória, na construção das diferenças de que somos feitos". Compreendido nesses termos, o conceito de identidade segue os pressupostos de Woodward

\footnotetext{
${ }^{5}$ Do original: “[...] how a person understands his or her relationship to the world, how that relationship is constructed across time and space, and how the person understands possibilities for the future".
} 
(2000), conforme os quais ela é: a) relacional, ou seja, depende de algo fora dela para existir; b) marcada pela diferença, pois se distingue por aquilo que ela não é; c) sustentada pela exclusão, embora haja, mesmo na exclusão, similaridades; d) marcada por símbolos, sendo tanto simbólica quanto cultural. A autora afirma também que "o processo de construção da identidade [...] é caracterizado por conflito, contestação e uma possível crise" (WOODWARD, 2000, p. 12).

Como coloca Serrani-Infante (1998), identidade é um conceito incompleto, está continuamente se estruturando e reestruturando, muitas vezes de forma contraditória, em intrincadas relações de poder mediadas pelo discurso. Na sequência, exploro como essas identidades são construídas.

\section{A construção do $e u$}

Como visto, identidades estão sempre em processo de construção e dependem do contexto de interação, o que implica a ideia de reconstrução, de reelaboração, por parte do indivíduo, dos significados que lhe são transmitidos pelo grupo cultural, ou seja, como mostra Woodward (2000, p. 30), "diferentes contextos sociais fazem com que nos envolvamos em diferentes significados sociais". Hall (2000, p. 106) argumenta que "a identificação é construída a partir do reconhecimento de alguma origem comum, ou de características que são partilhadas com outros grupos ou pessoas, ou ainda a partir de um mesmo ideal". Assim, os processos de identificação do indivíduo estão intimamente relacionados com o contexto no qual está inserido social, cultural, étnico, econômico etc. - e coexistem de forma conectada.

Para Norton (2000), a etnicidade, o gênero e a classe social são experienciados de modos complexos, entrelaçados na construção de identidade e no discurso, não como variáveis distintas no contexto. De modo semelhante, as identificações como alunos estão também entrelaçadas nessa construção. Silva $(2000$, p. 84) propõe que, apesar de possuir um caráter móvel, a tendência das identidades é a fixação:

o processo de produção da identidade oscila entre dois movimentos: de um lado, estão aqueles processos que 
tendem a fixar e a estabilizar a identidade; de outro, os processos que tendem a subvertê-la e a desestabilizá-la. [...] Tal como a linguagem, a tendência da identidade é para a fixação. Entretanto, tal como ocorre com a linguagem, a identidade está sempre escapando. A fixação é uma tendência e, ao mesmo tempo, uma impossibilidade.

As faces das identidades do indivíduo resultantes desses processos estão, assim, em constante desenvolvimento, tendendo a uma fixação que nunca alcançarão, pois todas as nossas interações cotidianas influenciam e são influenciadas por nossas identificações, que, por sua vez, são moduladas por uma língua/cultura, como discutido em seguida.

\section{A relação parametral entre língua e identidade}

Como afirma Brown (2000), língua e cultura estão tão intricadamente interligadas que não se pode separar as duas sem a perda de significância de língua ou de cultura, e a cultura estabelece um modelo de existência pessoal e social. Se língua e cultura são conceitos indissociáveis, e a nossa cultura nos fornece parâmetros para nossas identificações, a língua é o lugar onde o sentido de si e a nossa subjetividade são construídos (NORTON, 2000). É através da língua que os indivíduos coconstroem e negociam suas identidades.

Weedon (1992 apud NORTON, 2000, p. 8-9) define língua como "o lugar onde formas possíveis e atuais de organização social e suas consequências sociais e políticas são definidas e contestadas". Dessa maneira, os modelos fornecidos por nossa língua/cultura são os modelos de nossas identificações. Segundo Kramsch, "a língua pode ser estudada no seu contexto social, mas a língua em si é vista como um sistema de signos ou símbolos arbitrários aos quais é dada existência social através de sua referência a um contexto que está fora

\footnotetext{
${ }^{6}$ Do original: “[...] the place where actual and possible forms of social organization and their likely social and political consequences are defined and contested".
} 
da língua ${ }^{7} "$ (2000, p. 133, grifo no original). Esse apontamento nos mostra que, mesmo se não abarcada em seu contexto social, a língua necessita de um contexto para existir. Mey (1998) discute a relação parametral entre língua e sociedade, afirmando que

[a língua] é a expressão das necessidades humanas de se congregar socialmente, de construir e desenvolver o mundo. A língua não é somente a expressão da "alma" ou do "íntimo", ou do que quer que seja do indivíduo; é, acima de tudo, a maneira pela qual a sociedade se expressa como se seus membros fossem sua boca (MEY, 1998, p. 76-77, grifos no original).

Fabrício e Moita Lopes (2002, p. 13) apontam que a linguagem não mais deve ser compreendida como representativa da vida social, mas como constitutiva da vida social, na qual "os indivíduos passam a ser compreendidos como agindo em práticas discursivas específicas que os constituem em certas direções de forma situada e contingente". Isso significa que a língua é constitutiva também do sujeito social e media seus processos de identificação. Segundo Mey (1998), essa relação do indivíduo com a língua é tão intensa que não conseguimos definir uma pessoa separadamente da sociedade, ainda que cada um de nós tenha determinadas "marcas de autenticidade". Os autores mostram a relação indissociável da identidade com a língua e com o contexto quando afirmam que

não existe princípio da identidade desvinculado de uma prática coletiva e de determinado contexto social que lhe dê sentido e articule consequências convencionalizadas. Por este ângulo, haveria um vínculo indissociável entre linguagem, sociedade, contexto, comportamento e atividades humanas (FABRÍCIO; MOITA LOPES, 2002, p. 16).

\footnotetext{
${ }^{7}$ Do original: "Language can be studied in its social context, but language itself is seen as a system of arbitrary signs or symbols that are given social existence through their reference to a context which is itself outside of language".
} 
Contudo, conforme esclarecem Hansen e Liu (1997 apud MAHER, 1998), a identidade social deveria ser explorada como um contínuo dinâmico que permitisse a fatores diversos, não somente a língua, se inter-relacionarem de um modo complexo, sem inícios, nem fins. Isso porque a identidade não está alojada apenas na materialidade linguística (língua): a identidade é sempre uma questão discursiva, o que inclui a historicidade e o ideológico (MAHER, 1998). Assim, ao aprendermos uma LE, iniciamos um processo de identificação, o que vem discutido a seguir.

\section{Aprendizagem de LE: fonte de (re)construções identitárias}

Podemos partir da ideia de que o domínio afetivo relaciona-se intimamente com o processo de ensino/aprendizagem de LE. Brown (2000, p. 143) afirma que "o domínio afetivo é o lado emocional do comportamento humano e deve ser justaposto ao lado cognitivo". O autor aborda o tema das variáveis socioculturais que emergem enquanto o aprendiz de segunda língua põe não somente duas línguas em contato, mas duas culturas e, assim, aprende uma segunda cultura juntamente com uma segunda língua. Segundo Brown (2000, p. 182),

a aprendizagem de uma cultura é um processo de criação de significados compartilhados entre representantes culturais. É experiencial, um processo que continua ao longo de anos de aprendizagem de língua, e penetra profundamente nos padrões de pensamento, sentimento e ação. A aprendizagem de segunda língua [...] envolve a aquisição de uma segunda identidade ${ }^{9}$.

Kramsch (2000, p. 133) afirma que o aprendizado de uma língua pode ser definido como "um processo dialógico de significação,

\footnotetext{
${ }^{8}$ Do original: "The affective domain is the emotional side of human behavior, and it may be juxtaposed to the cognitive side".

${ }^{9}$ Do original: "Culture learning is a process of creating shared meaning between cultural representatives. It is experiential, a process that continues over years of language learning, and penetrates deeply into one's patterns of thinking, feeling, and acting. Second language learning [...] involves the acquisition of a second identity".
} 
troca e interpretação que constrói o indivíduo assim como constrói o outro $^{10 \%}$. Dessa maneira, aprender uma LE é um processo de significação e construção identitária. Complementarmente, cito Serrani-Infante (1998, p. 256-257), que aponta que

o encontro com segundas línguas talvez seja umas das experiências mais visivelmente mobilizadoras de questões identitárias no sujeito. [...] De um lado é uma experiência mobilizadora em direção ao novo, mas pelo mesmo movimento, ao serem solicitadas as bases mesmas da estruturação subjetiva, e com isso a língua materna, a experiência mobilizadora mais determinante é a que afeta substancialmente as discursividades fundadoras, constitutivas do sujeito. As posições subjetivas nunca serão as mesmas depois do processo de inscrição em discursividades de segunda(s) língua(s).

Sobre a questão, Norton (2000) aponta que, ao mesmo tempo em que é importante para o aprendiz aprender as regras de uso de uma língua, é igualmente importante aprender o que é considerado uso apropriado da língua de acordo com as inesgotáveis relações de poder entre os interlocutores. E se os aprendizes não fazem progressos na aprendizagem não se pode determinar que não estão motivados ou que não desejam aprender uma LE. A autora mostra ainda que quando aprendizes de língua falam, eles não estão somente trocando informações com falantes da língua-alvo, mas estão constantemente organizando e reorganizando um senso de quem eles são e de como se relacionam com o mundo social. Assim, "um investimento na línguaalvo é também um investimento na identidade do aprendiz, uma identidade que está constantemente mudando através do tempo e do espaço $^{11 "}$ (NORTON, 2000, p. 11).

Segundo a autora, os teóricos de aquisição de segunda língua devem desenvolver uma concepção do aprendiz de língua como tendo

${ }^{10}$ Do original: “[...] a dialogic process of sign making, exchanging, and interpreting that constructs the self as it constructs the other".

${ }^{11}$ Do original: "[...] an investment in the target language is also an investment in a learner's own identity, an identity which is constantly changing across time and space". 
uma identidade social complexa e relacionada às estruturas sociais reproduzidas na interação. Tomando essa posição, a autora põe em primeiro plano o papel da língua como "constitutiva e constituída da identidade do aprendiz de língua" (NORTON, 2000, p. 5). Vereza (2002) discute duas possíveis fontes de estranhamento que caracterizam a produção do discurso em LE: a) ao se confrontar com o paradigma do falante nativo, este pode passar a representar um alvo do aprendiz e acabar lembrando a muitos o quão longe ou perto seu discurso estaria do ideal; e b) a relação do indivíduo com sua própria língua materna. Desse modo, afirma que "essa mútua apropriação, ou seja, o processo por meio do qual o sujeito apropria-se de sua língua e por ela é apropriado, implica inevitavelmente construção de subjetividade ou identidade" (VEREZA, 2002, p. 352).

A autora retoma a função intersubjetiva da linguagem para argumentar que aprender uma língua é "construir uma realidade para si mesmo, é impor alguma forma à experiência e, ao mesmo tempo, é ser construído e se construir para essa mesma realidade que só é acessível ao sujeito via língua". E, segundo a autora, "no caso específico do discurso em língua estrangeira, o vínculo linguagem-realidade e identidade é, pelo menos parcialmente, desnaturalizado" (VEREZA, 2002, p. 353).

O espaço de sala de aula é um espaço per se de interação. É um ambiente de múltiplas vozes onde se dá um processo de ensino/aprendizagem. Trazemos para esse ambiente experiências e conhecimentos e assumimos determinadas identidades. E, quando interagimos em sala de aula, estamos influenciando e sendo influenciados, em um processo contínuo de significação, que, segundo a visão socioconstrucionista, é entendida como resultado de processos de interação social. Então, nos tornamos aprendizes.

\section{O tornar-se aluno}

Aprendizes de LE trazem, para a sala de aula, uma gama de conhecimentos prévios e gerais sobre o mundo de que podem se aproveitar para ajudá-los a compreender o insumo em LE. Se, nas interações de sala de aula, cada um traz consigo subjetividades, que incluem os pensamentos conscientes e inconscientes e emoções do 
indivíduo, a sua percepção, o seu modo de entender o mundo e com ele relacionar-se (WEEDON, 1992 apud NORTON, 2000), essas subjetividades se relacionam em um constante processo de (re)significação.

Dessa maneira, a interação em sala de aula exerce papel fundamental, e a ideia de aprendizado inclui a interdependência dos indivíduos envolvidos no processo (OLIVEIRA, 1993). Como coloca a autora, a síntese de dois elementos prevê um "componente novo [que] não estava presente nos elementos iniciais: foi tornado possível pela interação entre esses elementos, num processo de transformação que gera novos fenômenos" (OLIVEIRA, 1993, p. 23).

Weedon (1992 apud NORTON, 2000) aponta que a subjetividade é um lugar de interpretação do outro, e não uma representação do mundo real, uma vez que a subjetividade está atravessada pela linguagem e esta não é transparente. Sobre o tema, Moita Lopes (2003, p. 20) afirma que "aquilo que a pessoa é, ou sua identidade social, é exatamente o que é definido nos e pelos discursos que a envolvem ou nos quais ela circula e [...] a constroem, ainda que tais discursos possam ser combinados e ambíguos". De acordo com Fabrício e Moita Lopes (2002, p. 17), "nossa fabricação identitária é um processo intersubjetivo, dialógico e relacional, pois os efeitos de sentido criados estão sempre submetidos ao olhar do outro, sendo afetados pelo contexto emergente".

Kramsch (2000) descreve como aprendizes enfrentam as complexidades da vida de sala de aula e argumenta que os alunos usam o sistema educacional para promover suas significações locais e pessoais e prazer, de acordo com seus propósitos de aprendizagem. Algumas das decisões dos aprendizes podem incluir resolver fazer um curso, erguer a mão em sala, fazer os deveres de casa, ler, assistir programas na língua-alvo e falar com falantes nativos. Os indivíduos acham significações nas situações que vivem, nas modificações e adaptações que fazem para resolver problemas em sua vida cotidiana. A autora afirma que "em um mundo de signos motivados e reversíveis, tudo coexiste com todo o resto e adquire significado, ou seja, 
existência, somente através de suas relações com outros ${ }^{12,}$ (KRAMSCH, 2000, p. 139).

Nessa perspectiva, a experiência individual e poder social estão relacionados, pois a subjetividade é produzida em diversos lugares sociais, os quais são, todos, estruturados pelas relações de poder, e é a partir dessas relações que a pessoa assume diferentes posições subjetivas, tais como professor e aluno. Essas relações podem ser conflituosas, uma vez que o sujeito não é passivo e a língua que o permeia, por meio do discurso, é um lugar de luta, mudanças e contestações; e essas relações de poder podem promover ou limitar a variedade de identidades dos aprendizes de línguas (NORTON, 2000). É inegável, portanto, que as identidades têm papel fundamental no processo de ensino/aprendizagem de LE e têm o potencial de limitar ou ampliar nossas possibilidades nesse processo.

\section{Palavras finais}

Identidades são um construto essencial por nos apresentarem ao mundo e a nós mesmos; nossas identidades nos posicionam no mundo. No ambiente de aprendizagem de LE, colocamos (pelos menos) duas línguas em contato, o que pode acionar um processo de (re)construção de identidades. Associado a isso, segundo Silva (2000, p. 92), há a necessidade de se oferecer oportunidades para que os alunos desenvolvam "capacidades de crítica e questionamento dos sistemas e das formas dominantes de representação da identidade e da diferença". Sobre a questão, Moita Lopes (2003, p. 17) acrescenta que

a necessidade de estudar as identidades sociais se explica pelo grande momento de reflexividade que vivemos na vida contemporânea, no que alguns chamam de modernidade tardia, sobre os modos atuais de experienciar a vida social ou as novas identidades sociais que se apresentam.

\footnotetext{
${ }^{12}$ Do original: "In a world of motivated and reversible signs, everything co-exists with everything else and acquires meaning, i.e. existence, only trough its relation with others".
} 
Nas (re)construções de significado da vida contemporânea, investigar as identidades no processo de ensino/aprendizagem de LE irá contribuir para que temas relacionados a esse novo modo de viver sejam abordados nas pesquisas. Afinal, como afirma Norton (2000), na pesquisa de aquisição de LE, há uma dificuldade para conceitualizar a relação entre o aprendiz de língua e o mundo social porque ainda não se desenvolveu uma teoria de identidade abrangente que integre o aprendiz de língua e o contexto de aprendizagem de língua.

Assim, pesquisar sobre identidades no âmbito do processo de ensino/aprendizagem de LE mostra-se relevante, pois, como aponta Serrani-Infante (1998, p. 258), "é fundamental repensar-se o conceito de identidade em termos de sedimentação de processos identificatórios do sujeito em face de diferentes línguas e discursos". A pesquisa cumprirá seu papel se chegar a sensibilizar os agentes envolvidos no processo e ensino/aprendizagem de LE para a importância da questão das identidades nesse processo e, assim, promover melhorias e desenvolvimento.

\section{Referências}

ALLENDOERFER, Cheryl. Creating "vietnamerican" discourse: ethnic identity in ESL classroom. Paper. Montreal, Canadá, 1999.

BROWN, H. Douglas. Principles of language learning and teaching. 4th ed. New York: Longman, 2000.

CASTRO, Regina A. Leão. Salas de bate-papo na internet: espaço onde as mulheres tecem sua identidade através da linguagem. Tese (Doutorado em Estudos Lingüísticos e Literários em Inglês) Universidade São Paulo, São Paulo, 2006.

CAVALLARI, Juliana Santana. Identificação elou apagamento do sujeito da língua materna frente ao processo de ensino de inglês como LE. Dissertação (Mestrado em Lingüística Aplicada) - Universidade Estadual de Campinas, Campinas, SP, 2002. 
DUFF, Patricia A. The discursive co-construction of knowledge, identity and difference: an ethnography of communication in the high school mainstream. Applied Linguistics, v. 23, n. 3, p. 289-322, 2002.

ECKERT-HOFF, Beatriz M. O falar de si como (des)construção de identidades e subjetividades no processo de formação do sujeitoprofessor. Tese (Doutorado em Lingüística Aplicada) - Universidade Estadual de Campinas, Campinas, 2004.

HALL, Stuart. A identidade cultural na pós-modernidade. Trad. Tomaz Tadeu da Silva, Guacira Lopes Louro. 7. ed. Rio de Janeiro: DP\&A Editora, 2003.

. Quem precisa da identidade?. Trad. Tomaz Tadeu da Silva. In: SILVA, Tomaz Tadeu (Org.). Identidade e diferença: a perspectiva dos estudos culturais. 3. ed. Petrópolis: Vozes, 2000. p. 103-133.

FABRÍCIO, Branca Falabella; MOITA LOPES, Luiz Paulo. Discursos $e$ vertigens: identidades em xeque em narrativas contemporâneas, Veredas, Juiz de Fora, v. 6, n. 2, jul./dez. 2002.

FONSECA, Ana Silvia A. Além da "inadequação gramatical”: visão discursiva das instabilidades do "eu" em aprendizes de português L2. Dissertação (Mestrado em Lingüística Aplicada) - Universidade Estadual de Campinas, Campinas, 2002.

FREITAS, Déborah de Brito A. P. Escola Makuxi: identidades em construção. Tese (Doutorado em Lingüística Aplicada) - Universidade Estadual de Campinas, Campinas, 2004.

KRAMSCH, Claire. Social discursive constructions of self in L2 learning. In: LANTOLF, James P. Sociocultural theory and second language learning. Oxford: Oxford University Press, 2000. p. 133-153.

MAHER, Tereza Machado. Sendo índio em português... In: SIGNORINI, Inês (Org.). Língua(gem) e identidade: elementos para uma discussão no campo aplicado. 2. ed. Campinas, SP: Mercado das Letras; São Paulo: Fapesp, 1998. p. 115-138. 
MEY, Jacob L. Etnia, identidade e língua. Trad. Maria da Glória de Moraes. In: SIGNORINI, Inês (Org.). Língua(gem) e identidade: elementos para uma discussão no campo aplicado. 2. ed. Campinas, SP: Mercado das Letras; São Paulo: Fapesp, 1998. p. 69-88.

MOITA LOPES, Luiz Paulo. Socioconstrucionismo: discurso e identidade social. In: MOITA LOPES, Luiz Paulo (Org.). Discursos de identidades: discurso como espaço de construção de gênero, sexualidade, raça, idade e profissão na escola e na família. Campinas, SP: Mercado das Letras, 2003. p. 13-38.

NORTON, Bonny. Identity and language learning: gender ethnicity and educational change. Londres: Longman, 2000.

OLIVEIRA, Marta Kohl. Vygotsky: Aprendizado e desenvolvimento: um processo sócio-histórico. São Paulo: Scipione, 1993.

OLIVEIRA, Sônia Regina N. Da dificuldade da produção oral à construção do indivíduo-aprendiz-adulto em língua francesa. Dissertação (Mestrado em Língua e Literatura Francesa) Universidade de São Paulo, São Paulo, 2008.

PARK, Jae Eun. Co-construction of nonnative speaker identity in cross-cultural interaction. Applied Linguistics, v. 28, n. 1, p. 339-360, 2007.

PEREIRA, Giselda Fernanda. A identidade cultural no processo de aprendizagem do português língua estrangeira (PLE) no Brasil. Dissertação (Mestrado em Filologia e Língua Portuguesa) Universidade de São Paulo, São Paulo, 2005.

PEIRCE, Bonny Norton. Social identity, investment, and language learning. TESOL Quarterly, v. 29, n. 1, p. 9-31, 1995.

RICHARDS, Keith. 'Being the teacher': identity and classroom conversations. Applied Linguistics, v. 27, n. 1, p. 51-77, 2006. 
ROSSI, Eliane Cavalher S. A construção do conhecimento e da identidade profissional do professor de inglês. Dissertação (Mestrado em Estudos da Linguagem) - Universidade Estadual de Londrina, Londrina, 2004.

SERRANI-INFANTE, Silvana. Identidade e segundas línguas: as identificações no discurso. In: SIGNORINI, Inês (Org.). Língua(gem) e identidade: elementos para uma discussão no campo aplicado. 2. ed. Campinas, SP: Mercado de Letras; São Paulo: Fapesp, 1998. p. 231264.

SIEGEL, Meryl. The role of learner subjectivity in second language in sociolinguistic competence: western women learning Japanese. Applied Linguistics, v. 17, n. 3, p. 356-382, 1996.

SILVA, Tomaz Tadeu. A produção social da identidade e da diferença. In: SILVA, Tomaz Tadeu (Org.). Identidade e diferença: a perspectiva dos estudos culturais. 3. ed. Petrópolis, RJ: Vozes, 2000. p. 73-102.

SOUSA, Renata Maria R. Q. Professores de inglês na escola pública: investigações sobre suas identidades numa rede de conflitos. Dissertação (Mestrado em Estudos Lingüísticos e Literários em Inglês) - Universidade de São Paulo, São Paulo, 2006.

TÁPIAS-OLIVEIRA, Eveline Mattos. Construção identitária profissional no ensino superior: prática diarista e formação do professor. Tese (Doutorado em Lingüística Aplicada) - Universidade Estadual de Campinas, Campinas, 2006.

TSE, Lucy. The effects of ethnic formation on attitudes toward ethnic language development. Paper. New York, NY, 1996.

VARONIS, Evangeline Marlos; GASS, Susan. Non-native/non-native conversations: a model for negotiation of meaning. Applied Linguistics, v. 6, n. 1, p. 71-90, 1985.

VEREZA, Solange C. Quem fala por mim?: Identidade na produção discursiva em língua estrangeira. In: MOITA LOPES, Luiz Paulo; 
O eu e a nova língua: identidades e ensino/aprendizagem

BASTOS, Liliane Cabral (Orgs.). Identidades: recorte multi e interdisciplinares. Campinas, SP: Mercado de Letras, 2002. p. 351361.

WOODWARD, Kathryn. Identidade e diferença: uma introdução teórica e conceitual. Trad. Tomaz Tadeu da Silva. In: SILVA, Tomaz Tadeu (Org.). Identidade e diferença: a perspectiva dos estudos culturais. 3. ed. Petrópolis, RJ: Vozes, 2000. p. 7-72.

Recebido em: 12/05/2010 Aceito em: 11/12/2011

Title: The self and the new language: identities and foreign language learning and teaching 